\title{
Latency and duration of the action interruption in surprise
}

\author{
Gernot Horstmann \\ Bielefeld University, Germany
}

\begin{abstract}
Cognitive and biological theories of emotion consider surprise as an emotional response to unexpected events. Four experiments examined the latency and the duration of one behavioural component of surprise: The interruption of ongoing action. Participants were presented with an unannounced visual event- the appearance of new perceptual objects - during the execution of a continuous action - a rapid alternate finger tapping - which allowed a precise measurement of the latency, and the duration of an action interruption induced by the surprising event. Of the participants, $78 \%$ interrupted the tapping with a mean latency of 214 $\mathrm{ms}$ and a mean duration of $995 \mathrm{~ms}$. Variations of the number and perceptual heterogeneity of the new objects revealed that the perceptual analysis of the surprising event contributes significantly to the interruption duration.
\end{abstract}

When theorists consider which emotions are controlled by the evolutionary moulded, culturally universal mechanisms that have guided our ancestors through their environments, surprise is often among those mentioned (e.g., Darwin, 1872; Eibl-Eibesfeld, 1997; Ekman, 1972; Frijda, 1986; Izard, 1977; Panksepp, 1992; Tomkins, 1984; Plutchik, 1980, 1984). According to this evolutionary account, surprise is an adaptive response to unexpected events. In short, the psychological adaptation of surprise promotes-by means of reorienting attention and interrupting action-cognitive and motivational processes that are directed at a proper understanding of the unexpected event, and ultimately, at fitness-enhancing responses to unforeseen situational changes.

Surprise is also often among the cardinal emotions that are accounted for by appraisal theories (e.g., Roseman, 1991; Scherer 1984a, 1984b). Although

Correspondence should be addressed to Gernot Horstmann, Department of Psychology, Bielefeld University, POB 100 131, 33501 Bielefeld, Germany; e-mail: gernot.horstmann@uni-bielefeld.de

This research was supported by a grant from the Deutsche Forschungsgemeinschaft (ME 708/4-1) to Wulf-Uwe Meyer. I am indebted to Sabine Dlugosch, Kathrin Holtmann, and Lydia Wittenbreder for conducting the experiments, to Lily-Maria Silny for her assistance in manuscript preparation, and to Stefanie Becker, Wulf-Uwe Meyer, and two anonymous reviewers for their comments on a previous version of the manuscript.

(C) 2006 Psychology Press Ltd 
surprise is distinct from other emotions because its feeling component lacks a strong hedonic valence, it is probably also important for the valenced emotions, such as happiness, anger, or fear: Through surprise, important information that might otherwise be ignored is analysed, appraised, or reappraised (e.g., Lazarus, 1991; Meyer, Reisenzein, \& Schützwohl, 1997; Weiner, 1986). Unexpectedness actually figures prominently in Scherer's (1984a, 1984b) process model of appraisals: Together with novelty, unexpectedness is the first target of a sequence of stimulus evaluation checks. Moreover, Scherer (1984a, 1984b; Leventhal \& Scherer, 1987) assumes that the novelty/unexpectedness check triggers the execution of other appraisal processes (Weiner, 1986, expressed a similar view with respect to emotion-relevant attribution processes). This hypothesis is supported, for example, by Roseman, Antoniou, and Jose's (1996) study on appraisal determinants of emotions, where most emotion-eliciting events were, on average, somewhat unexpected (see also Frijda, Kuipers, \& ter Schure, 1989). Thus, surprise frequently constitutes an early stage in emotion elicitation that merges with other emotions (e.g., happiness, anger, or sadness), which follow it (see Shand, 1914).

\section{The surprise module}

In this paper, I will assume an evolutionary perspective and conceive of the mechanism underlying surprise as an evolved emotion module (e.g., Meyer et al., 1997). An emotion module basically comprises a detector and a response programme (see Reisenzein \& Horstmann, in press, who refer to McDougall's, 1908, instinct theory of evolved emotions; see also Öhman \& Mineka, 2001 and Tooby \& Cosmides, 2000, for more recent descriptions of evolved modules). Adequate stimulation excites the detector, which in turn activates the response programme. The response programme, finally, triggers changes in physiology, behaviour, cognition, and consciousness. In the case of surprise, these changes include the interruption of ongoing cognitive and motor processes (e.g., Darwin, 1872; Horstmann, 2001, 2002; Horstmann \& Schützwohl, 1998; Meyer, Niepel, Rudolph, \& Schützwohl, 1991; Meyer et al., 1997; Niepel, 2001; Niepel, Rudolph, Schützwohl, \& Meyer, 1994; Plutchik, 1980; Scherer, 1984a; Shand, 1914), the reorienting or refocusing of attention (Horstmann, 2002, in press-a, in press-b; Meyer et al., 1991; Wilcocks, 1928), the feeling of surprise (e.g., Reisenzein, 2000; Schützwohl \& Krefting, 2001), the arousal of epistemic motivation (Stiensmeier-Pelster, Martini, \& Reisenzein, 1995), physiological changes, such as bradycardia and the galvanic skin response (e.g., Niepel, 2001), and possibly other changes (such as the tendency to show a particular facial expression, Reisenzein, 2000).

Surprise is triggered by events that deviate from expectations (or, what is equivalent in the present treatment, the mental model of the present situation). More precisely, the detector of the surprise module is assumed to monitor 
through a continuous, automatic, and nonconscious process the coherence of ongoing events with the dynamic mental model of the situation (cf. Neisser, 1976; Rumelhart, 1984). The mental model incorporates expectancies in the sense that on its basis, certain aspects of the situation (e.g., objects, actors, or actions) are assumed to be present rather than others, and certain changes in the situation are assumed to occur rather than others. The mental model of the present situation allows an anticipation of immediately forthcoming changes (events), and is thus the computational basis for fast and smooth preplanned-in contrast to reactive- - behaviour.

In the present context, the concept of expectancy is not restricted to consciously represented guesses about the future, or intentional hypothesis testing. Rather, the vast majority of the expectancies are thought to be implicit and have no conscious reflection, whereas conscious expectancies, and a conscious desire to test them, occur only in specific circumstances (e.g., when a personal important goal-state is about to be realised). Explicit and implicit expectancies probably differ in their complexity. Explicit expectancies can - in principle-be indefinitely complex and specific. In contrast, implicit expectancies are usually simpler and less specific. One reason for the lack of specificity is that implicit expectancies are based on schemas, which in turn represent the typical appearance and actions of events, actors, and situations, and which are formed as abstractions from past (and often numerous) experiences (e.g., Rumelhart, 1984; Rumelhart \& Norman, 1978). Implicit expectancies are assumed to exist at all levels of representation, and the discrepancy detector is accordingly assumed to automatically detect a wide range of discrepancies, such as an event's unexpected appearance concerning time or space, its unexpected perceptual appearance, or its implications that are assessed on the level of autobiographic or semantic processing levels.

Most encountered events are coherent with the mental model and can thus be responded to as planned (i.e., according to the intended course of action). Moreover, the emotional meaning of an expected event (i.e., its appraisal) is incorporated in the mental model and thus also immediately available when the expected event occurs (e.g., Reisenzein, 2001). In contrast, an event that is incongruent with (or discrepant to) the mental model poses a problem for the currently pursued course of action in two respects: first, the discrepant event has not been considered in previous action planning, implying that its relevance to current short-lived and enduring goals has yet to be determined. For example, if, after work, on reaching my car, I were to find the door open, I might have second thoughts about getting in and driving away as usual. Second, the discrepant event questions the premises on which the mental model is based. For example, the detection of the open door would challenge my conviction that the university parking lot is a relatively safe place.

The deviation of an event from expectancy is assumed to be treatable as a quantity, and surprise is elicited if this quantity exceeds some threshold. Saying 
that surprise is elicited is a short-cut for saying that the surprise module triggers certain changes, the most important ones being the interruption of ongoing cognitive and motor processing, the focusing of attention towards the surprising event, and the feeling of surprise. These three components are assumed to promote the analysis and evaluation of the surprising event as well as the updating of the knowledge base that underlies the action-guiding mental model in the following way (Meyer et al., 1997): (a) the focusing of attention renders the surprising information accessible to higher order cognitive processes, (b) the interruption of cognitive and motor processes reduces interference introduced by other cognitive and motor processes, that would impede or slow down stimulusanalysis and response-preparation processes targeted at the surprising event, and (c) the feeling of surprise signals the current state of surprise in consciousness, and may give an initial motivational impetus for those analyses and response processes that do not unfold automatically (some processes are presumably automatic and therefore do not need a motivational impetus, cf. Meyer et al., 1997).

\section{Experimental evidence}

Consistent with this model, Meyer et al. (1991; see also Niepel et al., 1994) showed that an unannounced change in the appearance of a task-irrelevant distractor delays the response to an imperative stimulus that follows it. Based on the assumption that surprise is elicited by events that deviate from expectations or cognitive schemas, Meyer et al. (1991) presented distractors (two words) with a constant appearance (in black letters on a white background) in the precritical trials to lure the participants to expect this appearance in the upcoming trials as well (see also, Wilcocks, 1928). The imperative stimulus was a dot that appeared above or below the words; the position of the dot was the discriminative feature for a two choice reaction time (RT) task.

In the critical trial, the appearance of one of the words was different from the precritical trials (white letters on a black rectangle) for the first time and without prior information. Note that the words, or their appearance, were completely irrelevant for the participants' task: There was thus no reason to attend to them at all, or to test explicit expectations about them. The results revealed a significant RT delay in the critical trial (indicating an action interruption), high ratings of surprise (indicating subjective surprise), and high recall rates for the discrepant word in an unannounced recall test (indicating attention to the word). The action-delaying effect of the display change in the critical trial was stronger with a $500 \mathrm{~ms}$ stimulus onset asynchrony (SOA) between the distractor and the imperative stimulus than with $0 \mathrm{~ms}$ SOA, indicating some initial inertia of the action interruption. Further, the action delay was also stronger with a $500 \mathrm{~ms}$ SOA than with a $2000 \mathrm{~ms} \mathrm{SOA}$, indicating that the effect is rather short-lived. This action-delaying effect for unexpected visual stimuli has been replicated 
frequently (e.g., Horstmann, 2002; Horstmann \& Schützwohl, 1998; Niepel et al., 1994; Schützwohl, 1998).

According to the surprise model by Meyer et al. (1997), these results are explained as follows. The response to the imperative stimulus is delayed because the pursuing of the RT task is interrupted, and the surprising event is analysed instead. In particular, the action delay can be analysed into four component processes: (1) the detection of the discrepancy; (2) the interruption of the present task; (3) the processing of the surprising event; and finally (4) the resumption of the RT task. The interruption is a direct and reflexive consequence of the discrepancy detection, enabling the immediate (analysis does not have to wait until other processes have finished) and efficient (analysis does not have to share processing resources with other tasks) analysis of the surprising event. The processing of the surprising event includes, most importantly, appraisal processes, such as the determination of the event's goal relevance and its implications for well-being (cf. Roseman et al., 1996; Scherer, 1984a). Only after these processes have arrived to the conclusion that no immediate action must be taken, is the interrupted task resumed.

\section{Objective 1: Revealing the interruption in a continuous action}

Examining the RT delay as an indicator of the action interruption has two drawbacks. First, a sceptic may object that a RT delay is not tantamount to an interruption: the RT delay may have resulted from a delayed beginning of the response-related processes rather than from an interruption of these processes after they began. That is, the assumption that ongoing actions are literally interrupted may be unfounded, and a weaker hypothesis may be correct, being that surprise issues a new urgent action goal (e.g., to explore the surprising event) such that other planned actions are deferred. Second, the RT delay always reflects the interruption latency plus the duration of the subsequent analysis of the surprising event, and to disentangle these effects is of interest.

The first aim of the present work was to provide direct evidence for an actioninterrupting effect of surprise, and to separately measure the latency of the action interruption and the duration of the action suspension. This was done by using the continuous-task paradigm (Horstmann, 2001; see also Horstmann, 2003, for an application of the continuous-task paradigm to voluntary action interruptions). The participants in this paradigm respond to stimuli that signal either to execute a continuous task, or to be inactive. The continuous task is a rapid alternate finger tapping (RAFT), where the two index fingers are used to tap two neighbouring keys in the lower row of a computer keyboard quickly and alternately. This task usually produces a record of approximately 10 taps (i.e., key depressions) per second, which can be used to infer whether the participant is tapping or not. An action interruption-whether intentional (as a response to a 
signal to stop), or involuntarily (as a response to a surprising stimulus) — can be easily assessed as a drop in tapping performance. Furthermore, the latency and the duration of the interruption can be estimated, as the beginning and the end of the interruption.

\section{Objective 2: Determining the latency of the action interruption}

Determining the latency of the action interruption is of interest for several reasons. The most comprehensive one is that the determination of mental processes and their temporal characteristics is a general aim of psychological research (e.g., Posner, 1978). Additionally, the timing of events is also relevant for more specific questions. Assuming that surprise is coordinated by an evolved surprise module, one would expect that the components of surprise are triggered quickly (e.g., Öhman \& Mineka, 2001). As outlined above, no conscious decisions are assumed to intervene between stimulus perception, discrepancy detection, and action suspension. This suggests that in the ideal case (see below), the action interruption would be triggered very fast. Analogous predictions can be derived from Scherer's (1984a, 1984b; Leventhal \& Scherer, 1987) theory, because the novelty/unexpectedness check relevant for surprise is assumed to be the very first to be accomplished. Measuring the latency of the action interruption was the main purpose of the present experiments.

A short reflection reveals that the latency of surprise cannot be consistent over different surprise-eliciting stimuli. Depending on the nature of the discrepancy, the stimulus processing would need different amounts of time: Detecting a cracking sound in a silent environment is probably faster than detecting a contradiction between a set of propositions. That is, sometimes, the simple perception of the presence of the stimulus is expectancy-discrepant, whereas in other cases, the very nature of the discrepancy requires higher cognitive processes. In the present experiments, the surprising event was chosen such that higher cognitive processes play no role; rather, it was the very presence of some of the stimuli in the critical trial that was intended to be surprising. This was done in order to estimate the very minimum of the latency of the action interruption.

\section{Objective 3: Determining factors influencing the duration of the action interruption}

The determination of factors that influence the interruption duration is important for two reasons. First and most important, it gives information about the processes that occur between the interruption and the resumption of the action.

The duration of the action interruption should vary with the effort necessary to analyse and evaluate the surprising event (Meyer et al., 1997) as well as with the difficulty of updating the knowledge base that had failed to predict the 
surprising event (e.g., Horstmann \& Schützwohl, 1998; Schützwohl, 1998). For example, Meyer et al. (1997) have shown that surprising stimulus substitutions that are easily recognised as action-irrelevant induce less interference in a concurrent RT task than changes whose action relevance is more difficult to determine. This result supports the assumption that the action relevance of an event is analysed before the action is resumed.

The present experiments tested the extent to which the interruption duration is affected by processes related to the perceptual analysis of the unexpected event. Clearly, before higher order appraisal and schema-updating processes can be successfully executed, it is important to know more about the exact nature of the unexpected event. This is particularly true in cases when the expectancy discrepancy is detected preattentively, that is, before attention is directed to the discrepant object (e.g., Horstmann, 2002; in press-a, in press-b). In this case, only the presence of the discrepancy, but no further detail about the unexpected event is initially available for processing, and further analysis of the surprising event demands the direction of attentional processes towards the event (e.g., Treisman \& Gelade, 1980; Wolfe, 1994). Additionally, Meyer et al. (1991) have assumed that one of the immediate responses to surprising events is the "discrepancy verification": One verifies that one has seen correctly, heard correctly, or has drawn the correct inferences. The discrepancy detection also often involves a perceptual analysis.

It was reasoned that the effort (and the duration) of the perceptual analysis of unexpected events depends on their characteristics, such as the number of objects that constitute the unexpected event, their homogeneity, complexity, meaningfulness, etc. In order to test whether a perceptual analysis of the surprising event is part of the processes occurring during the action suspension, the experiments varied factors assumed to affect the duration of the perceptual analysis, and assessed the effect of this manipulation on the duration of the action suspension.

A secondary aim was to identify conditions under which the action interruption can be elicited reliably and, beyond that, with duration long enough to ensure that it could be registered in an experiment with a high degree of reliability. It is clear that if the tapping is not suspended long enough, a genuine present action interruption would be very difficult to discriminate empirically from the naturally occurring intervals between consecutive taps. Tapping in this task proceeds normally with an average interval of $120 \mathrm{~ms}$ between two successive taps (interresponse interval; IRI, e.g., Horstmann, 2003), and although tapping performance is normally not very variable, naturally occurring IRIs between consecutive taps must be distinguished from the surprise-induced interruption by some specific criterion. The present experiments were partially conducted to establish experimental conditions for future research that maximise the number of participants that interrupt tapping at all and with an interruption long enough to identify it. 


\section{Overview of the present experiments}

Four experiments are reported. Participants worked on a task portrayed to assess the speed of starting and stopping a simple motor task. They were presented with a continuous stream of visual signals to perform the tapping or to rest. The signals were presented within a small frame at the centre of the screen. The participants engaged in three experimental blocks in total. At the end of the third block, one, four, or eight objects (depending on experiment and condition) appeared in parafoveal vision. These were the surprise stimuli. (Note that the term "surprise stimulus" is a verbal short-cut that denotes a stimulus that is intended to elicit surprise, analogously as the term orientating stimulus is used to denote the stimulus that is intended to elicit an orienting response.) When the surprise stimuli appeared, the participants had just (i.e., for a few seconds) started the tapping, and the stimuli were presented simultaneously with a signal to continue tapping. The presentation of the continue signal was done to ensure that there was no uncertainty that the tapping had to be continued when the surprise stimuli were presented.

Experiment 1 varied the number of objects presented in the surprise trial, with all objects being of the same type. Experiment 2 compared a condition with multiple instances of one object with a condition with the same number of different objects as surprise stimuli. Experiment 3 was based on the observation that the surprise stimuli in Experiments 1 and 2 were similar to the target display where the signals to tap or to rest were displayed, in that all stimuli were surrounded by a frame of the same size. Experiment 3 replicated the design of Experiment 2 but used new objects that were quite dissimilar to the target display: Schematic drawings of facial expressions (Musterle \& Rössler, 1986; see also Horstmann, 2002). Experiments 2 and 3 were based on the assumption that the analysis of different objects is longer lasting than the repeated analysis of multiple instances of the same object type. Experiment 4 again varied the number of presented objects, but in a different range ( 1 vs. 4$)$.

The main predictions can be summarised as follows. First, the presentation of the additional stimuli was assumed to trigger surprise. In particular, it was assumed that during the first two experimental blocks, a mental model was established that specified the general layout of the screen, and to which the very presence of the surprise stimuli was discrepant. It might seem that the surprising event tested here is of a very primitive variant, just consisting of a simple visual stimulus presented on the computer screen, with no personal meaning for the observer. However, current emotion theories assume expectancy discrepancy to be the sole condition for the elicitation of surprise (e.g., Meyer et al., 1997; Plutchik, 2003; Roseman, 1991; Roseman, Antoniou, \& Jose, 1996; see also Teigen \& Keren, 2003), and that personal meaning is assessed only after surprise in the narrower sense has occurred (e.g., Leventhal \& Scherer, 1987; Meyer et al., 1997; Scherer, 1984a, 1984b). As a manipulation check, the participants 
were asked, a few seconds after the surprising event, whether something unexpected had occurred in the last trial, and they rated the experienced surprise (or the lack of it) on a rating scale. Most importantly, however, participants were predicted to interrupt tapping immediately following the presentation of the surprise stimuli.

Second, the latency of the interruption was expected to be short, and possibly even shorter than the latency of the intentional interruption in response to the stop signals in the precritical trials. This prediction is suggested by the assumption that the detection of the discrepancy and the initiation of the interruption are automatic, and that the surprising event tested in the present experiments is one of the simplest possible variants.

Third, it was predicted that the duration of the action suspension would be longest when many objects were presented in the critical trial, and when these objects were perceptually different. This was predicted on the assumption that a perceptual analysis of the objects was conducted during the action interruption.

\section{EXPERIMENT 1}

In Experiment 1, participants performed the RAFT task, which required a response to the letters $T$ and $H$. The letter $T$ was the signal to tap, and the letter $H$ was the signal to rest. The letters appeared unpredictably in a random order, one at a time, such that each letter required a decision on whether the current action was to be changed or not. For example, in the sequence of signals H T T H H, the first letter $(\mathrm{H})$ signals to rest, the second letter $(\mathrm{T})$ signals to start tapping, the third letter $(\mathrm{T})$ signals to continue tapping, the fourth letter $(\mathrm{H})$ signals to rest (to stop tapping), and the last letter $(\mathrm{H})$ signals to continue resting. Because the letters were presented singly and because the identity of the forthcoming letter was unpredictable, each letter had to be identified and a decision with respect to its implications for action had to be made. The participants were instructed to respond quickly and accurately to the signals, and to tap fast and uniformly. Tapping here means that the participants rapidly alternated between pressing and releasing two different keys with the two index fingers (as when one types ghghghghg as fast as possible; actually the two response keys were the arrowleft and arrow-down keys in the lower row of the keyboard). No reference was made to the possibility of the presentation of additional stimuli in the course of the experiment; rather, participants were made to believe that the experiment dealt with the RTs and accuracy of the action changes (i.e., starts and stops) in the RAFT task. The critical trial, where the new objects ( 4 vs. 8 ) were presented to elicit surprise, occurred in the fourth block. The presentation of the new objects was preceded by a start signal to ensure that the participants were already tapping when the new objects appeared, and they were simultaneously presented with a continue tapping signal. 
Two groups were tested that differed only in the number of stimuli presented in the critical trial. It was reasoned that if the perceptual analysis is an important determinant of the duration of the action suspension, the duration should be longer with 8 than with 4 stimuli.

\section{Method}

Participants. Ten men and 23 women participated in the experiment. Their mean age was 23.9 years $(S D=3.2)$. Compensation was $2 \mathrm{DM}$ (about $€ 1$ ).

Apparatus. A microcomputer, equipped with an Intel 80486/100MHz CPU, with a keyboard and a 15 inch computer monitor, was used for stimulus presentation and response registration. Stimuli were presented with a resolution of $640 \times 480$ pixels and a refresh rate of $72.5 \mathrm{~Hz}$. Response keys were two adjacent keys on the lower row of the keyboard (arrow left and arrow down). ERTS (Experimental Run Time System; BeriSoft Cooperation) was used for event scheduling and reaction time measurement.

Design. Participants were randomly assigned to one of two experimental conditions that differed only in the surprise trial. In this trial, 4 or 8 new stimuli were presented.

Stimuli. All stimuli were composed of black pixels presented against a white background. Viewing distance was about $60 \mathrm{~cm}$. A stationary frame at the centre of the screen was presented through all the trials within a block. The frame subtended $1.7^{\circ} \times 1.7^{\circ}$ of visual angle. The letters $\mathrm{T}$ and $\mathrm{H}$, which served as signals to tap or halt, as well as the digits 1,2, and 3, which were used during a countdown to each experimental block, had a height of $0.4^{\circ}$ of visual angle. The new objects were all the same, each composed of a diamond-shaped quadrangle within a $1.7^{\circ} \times 1.7^{\circ}$ frame (Figure 1 ).

Procedure. Each block began with a 3 second presentation of the warning: "Please keep your index fingers near the response keys - the experiment will start immediately". The warning message was replaced by the stationary frame. In the centre of the frame, the digits 3,2 , and 1 were presented for $2 \mathrm{~s}$ each. This $6 \mathrm{~s}$ countdown was intended to enable the participants to prepare for the first signal. The signals were presented within the stationary frame by successively traversing four positions within the frame, each the $0^{\circ}$ (top), $90^{\circ}, 180^{\circ}$, and $270^{\circ}$ position of an imaginary circle. The onset of a new signal was simultaneous with the offset of the previous signal. Whereas the position of the next signal was predictable due to the clockwise rotation, the stimulus onset asynchrony (SOA) was not. Except for the last two signals presented in the experiment, the SOA varied randomly between $1200 \mathrm{~ms}$ and $3200 \mathrm{~ms}$ with an expectancy value of 


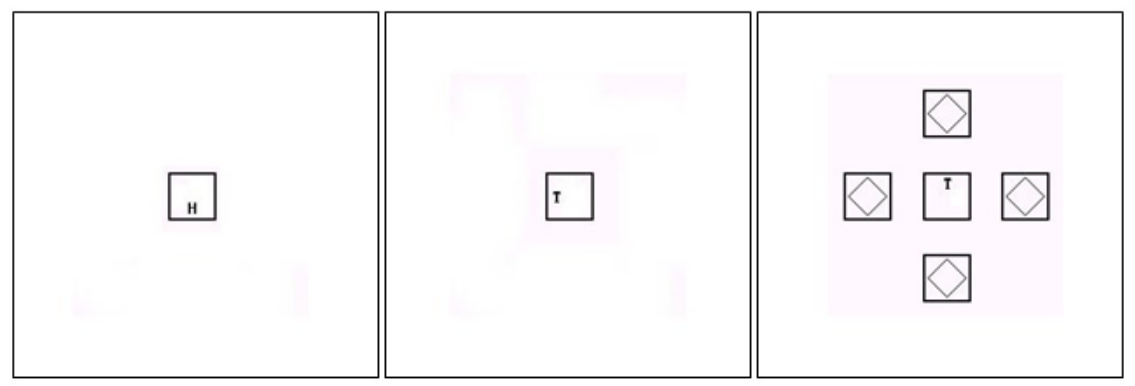

Figure 1. Examples of the experimental stimuli used in Experiment 1. The sequence shows the last two nonsurprise trials and the surprise trial.

$1600 \mathrm{~ms}$. The resulting time uncertainty was intended to reduce a tendency for anticipatory responses.

The first three blocks were random sequences of 10 signals to tap $(\mathrm{T})$ and 10 signals to halt $(\mathrm{H})$ each. The participants were instructed to tap fast and uniformly and to respond quickly and accurately to the signals. In particular, they were requested to start tapping only after the appearance of a $\mathrm{T}$, and to continue a fast and uniform tapping until the appearance of an $\mathrm{H}$. The first block served to familiarise the participants with the task. During this practice block, they were supervised by the experimenter; she encouraged the participants to tap rapidly and uniformly, and to respond rapidly to the signals while avoiding false or anticipatory responses. During the remaining three blocks, the experimenter occupied herself with another task outside the participant's field of vision.

The first 10 trials of the fourth block consisted of a unique random sequence of 5 signals to tap and 5 signals to halt. They were followed by the signal sequence $\mathrm{H}, \mathrm{T}, \mathrm{T}$, and $\mathrm{H}$ in fixed order. During the last two signals, the new objects were presented. Each of the last two signals was displayed for $1400 \mathrm{~ms}$. Depending on the experimental condition, 4 or 8 new objects were displayed. They were evenly distributed on the imaginary circumference of a circle with a radius of $3^{\circ}$, with one new object always located at the $0^{\circ}$ (top) position of the circle. The time of each key press was recorded time-locked to the onset of each signal (due to a technical restriction in the software used to control the experiment, the maximum number of key presses that could be recorded during one signal was 20 ).

Immediately after the last trial, the question: "Did you notice that something different appeared on the screen in the last trial? $(\mathrm{y} / \mathrm{n})$ "' appeared on the monitor. After the participants had typed in their answer, the next question appeared on the screen: "Please indicate the extent of surprise (if any) you experienced with respect to that change'. The participants rated their experienced surprise on an 11 -point rating scale anchored with $0=$ no surprise at all and $10=$ as surprised as possible, and entered the corresponding number using the keyboard. 


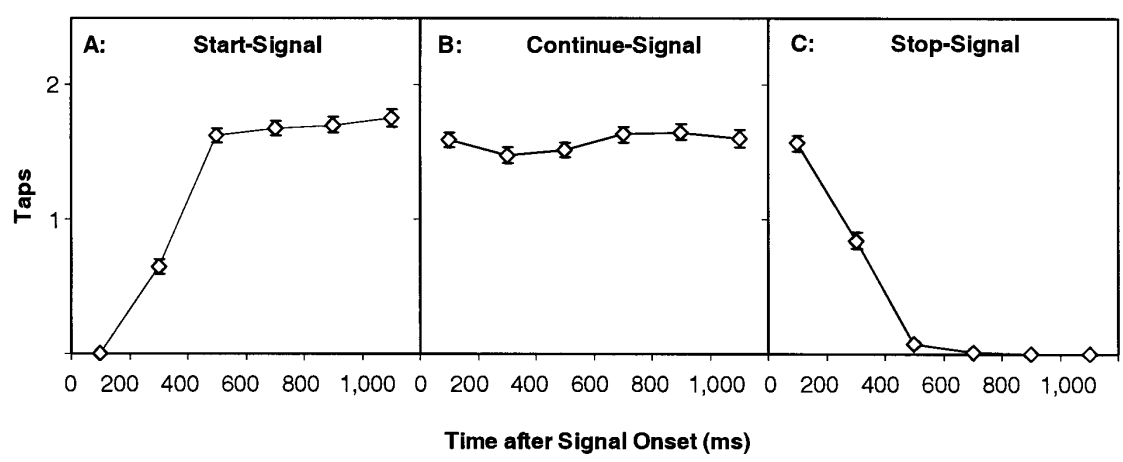

Figure 2. Time course of the tapping performance in the start tapping trials (A) continue tapping trials (B), and stop tapping trials (C), in the precritical trials from Experiment 1. The error bars show the standard errors of the means.

\section{Results}

Figure 2 shows the tapping performance within $1200 \mathrm{~ms}$ following the onset of a signal on start trials (a $\mathrm{T}$ following an $\mathrm{H}$ ), continue tapping trials (a $\mathrm{T}$ following a $\mathrm{T}$ ), and stop trials (an $\mathrm{H}$ following a $\mathrm{T}$ ) for the nonsurprise trials. Taps were accumulated within $200 \mathrm{~ms}$ time bins. Each data point represents the mean number of responses that fell within the time bin; for example, the first data point in the left panel of Figure 2 indicates that within the first $200 \mathrm{~ms}$ after the onset of the signal, almost no tap was recorded.

The mean interresponse interval (IRI), an indicator of tapping speed, was 120 $\mathrm{ms}(S D=23 \mathrm{~ms})$ in the start trials, $130 \mathrm{~ms}(S D=25 \mathrm{~ms})$ in the continue tapping trials, and $122(S D=30 \mathrm{~ms})$ in the stop trials. These results are comparable to those of previous experiments using the same tapping task and similar instructions (Horstmann, 2001, 2003).

Mean reaction time (RT) to the T in a start trial was $401 \mathrm{~ms}(S D=42 \mathrm{~ms})$. In the stop trials, the last tap was recorded at an average $255 \mathrm{~ms}(S D=53 \mathrm{~ms})$ after the onset of the H. As argued elsewhere (Horstmann, 2001, 2003), a reasonable estimation of stop reaction time (eSRT) as an analogue to RT can be obtained by adding half the mean IRI to the last tap time. Consistent with previous research, eSRT, with a mean of $316 \mathrm{~ms}(S D=51)$, was considerably shorter than RT, $t(32)$ $=9.94, p<.001$ (tests were two-tailed unless otherwise stated). This is probably due to minor requirements in response planning and response execution for an action termination as compared to an action initiation (Horstmann, 2003).

Whether the presentation of the new objects in the critical trial altered the tapping performance was tested in two ways. First, the total number of taps in the surprise trial was compared to the average total number of taps in the continue trials. Second, each bin in the surprise trial was compared with the 
corresponding bin in the precritical continue trials, to obtain information about the temporal characteristics of the interruption.

The presentation of the new objects dramatically changed the tapping performance. Significantly fewer responses were recorded in the surprise trial in the 4 stimuli condition, $t(15)=8.3, p<.001$, and in the 8 stimuli condition, $t(16)=$ $8.0, p<.001$. The reduction tended to be more pronounced in the 8 stimuli condition $(M=6.2, S D=3.2)$ than in the 4 stimuli condition $(M=4.6, S D=2.2)$, $t(31)=1.6, p=.06$ (one-tailed).

Figure 3 shows the time course analysis for the two groups, with closed symbols depicting the performance in the critical trial, and open diamonds the performance in the continue tapping precritical trials. As $t$-tests revealed, performance was significantly lower in each $200 \mathrm{~ms}$ interval, even in the first interval, where the difference was smallest, $t \mathrm{~s}(32)>1.83, p \mathrm{~s}<.05$ (one-tailed). To test whether the number of new objects influences the performance in the critical trial, the differences between each bin in the critical and in the precritical trials was computed as $\Delta_{\text {crit }} . t$-Tests revealed no differences in $\Delta_{\text {crit }}$ between the two groups in the first three bins (0-600) and in the fifth bin (800-1000 ms), ts $<$ 1 ; in the fourth and sixth bin (600-800 and 1000-1200 ms, respectively), however, $\Delta_{\text {crit }}$ was significantly greater with 8 than with 4 new objects, $t$ s (31) > $3.1, p \mathrm{~s}<.01$. This result indicates that the interruption latency was not influenced by the number of objects, but that 4 objects tended to be analysed faster than 8 objects.

Using the criterion suggested by Horstmann (2001), an interruption was defined as two successive $200 \mathrm{~ms}$ bins devoid of taps. According to this criterion, 26 of 33 participants (78\%) interrupted the tapping. No significant difference between the frequency of interruptions with 4 vs. 8 objects was obtained $(75 \%$ vs. $82 \%), \chi^{2}(1 ; N=33)<1$, Fisher's exact test, $p=.46$ (one-tailed). Of the seven participants who did not meet the criterion, five had at least one 200 ms interval devoid of taps, and only two participants had taps in all intervals. For those 26 participants who interrupted their tapping, the average last tap time was $162 \mathrm{~ms}(S D=81 \mathrm{~ms})$, which is considerably shorter than the average last tap time of the same participants in the nonsurprise trials $(M=254 \mathrm{~ms}, S D=56 \mathrm{~ms})$, $t(25)=5.8, p<.001$. The number of stimuli presented had no significant impact on the last tap time, $t(24)<1$.

For those participants who interrupted the tapping, the interruption duration was computed in the following way. If a participant interrupted the tapping but resumed it during the trial, the interruption duration was simply the difference between the times of the tap that defined the interruption (i.e., the last tap before the interruption and the first tap after the interruption). Alternatively, if a participant interrupted the tapping without resuming it, the interruption duration was the interval between the last tap and the disappearance of the letter (the continue signal that appeared simultaneously with the new objects). That is, the maximum possible interruption duration was $1399 \mathrm{~ms}$, assuming that the last tap 

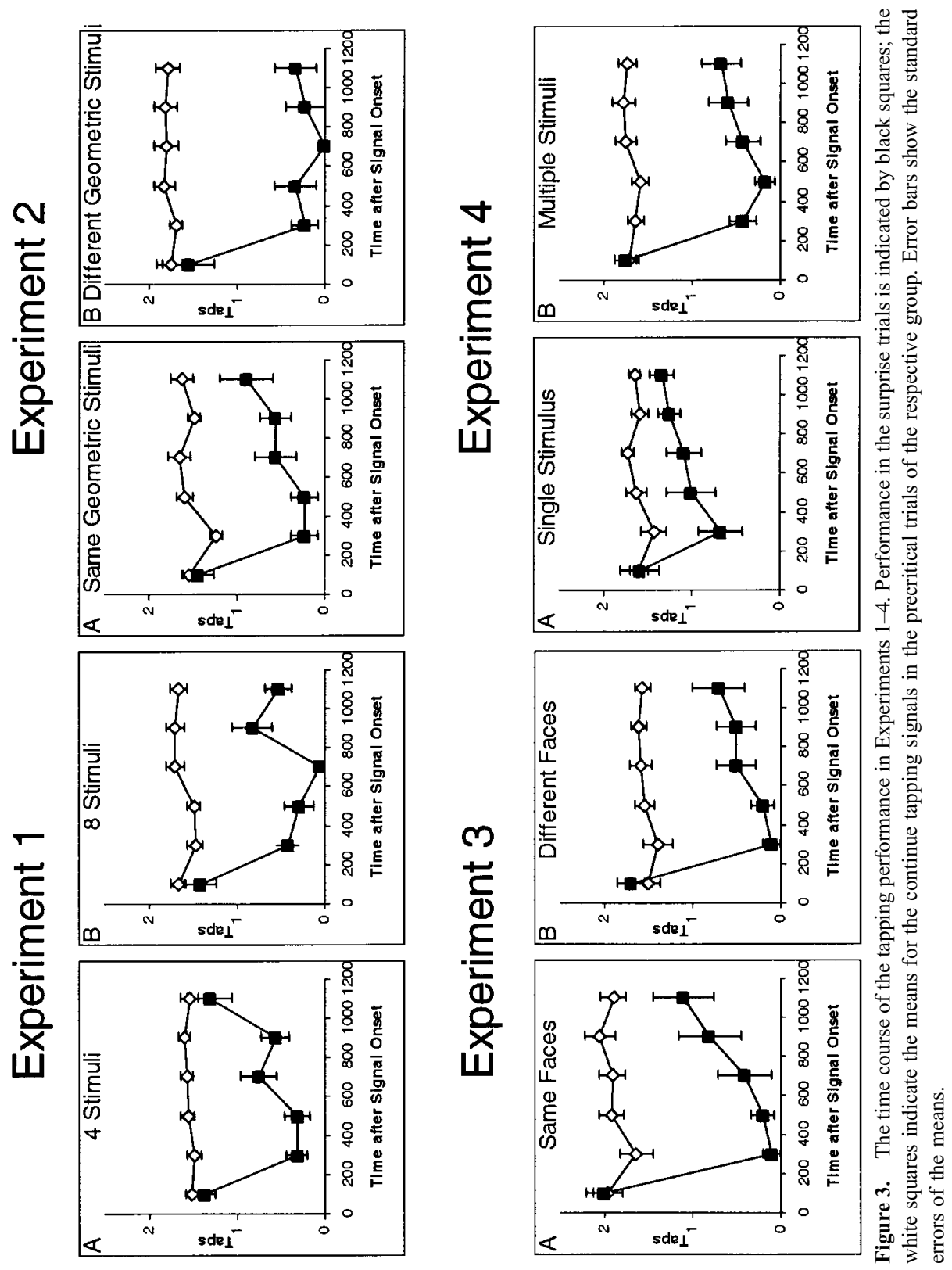
occurred $1 \mathrm{~ms}$ after the onsets of the letter and the new objects, and that tapping was not resumed until the next letter (i.e., the stop signal that was the last presented signal in the experiment) appeared. Although there was a tendency towards a somewhat longer interruption duration in the group with eight new stimuli, the difference was not significant, $t(24)=1.3, p=.21$. The mean interruption duration was $974 \mathrm{~ms}(S D=278 \mathrm{~ms})$.

There was no significant difference in rated surprise between the two experimental conditions, $t(31)<1$. The mean surprise rating was $7.0(S D=2.2)$, indicating medium to high degrees of surprise.

\section{Discussion}

The results of the present experiment confirmed the prediction that surprising events cause an interruption of ongoing processes, in particular of overt motor behaviour. The results are thus consistent with prior research (e.g., Meyer et al., 1991) and validate the interpretation of RT delays as indicating an action interruption in similar experiments. Indeed, about $80 \%$ of the participants interrupted the tapping according to a rather conservative criterion (two consecutive $200 \mathrm{~ms}$ bins devoid of taps), indicating a strong and robust phenomenon.

The interruption latency was low, with an eSRT of $223 \mathrm{~ms}$, and last tap time was even shorter in the critical trial than in the precritical trials. The very short latency thus supports the assumption that the interruption is triggered involuntarily, that is, without involvement of conscious decisions. Note that due to the nature of the surprising event, with the unexpectedness relating to the mere presence of the new objects, this short latency probably constitutes a minimum and that for other surprising events, for example, when the presence of an object is expected but not its identity, the latency may well be longer.

The number of new objects had no significant effect on the interruption latency, or the rated surprise, and a weak (nonsignificant) influence on the duration of the action suspension, the duration being slightly longer with 8 than with 4 stimuli. The results concerning latency and duration were mirrored in the time course analysis, with no differences between 8 and 4 stimuli in the first three bins (0-600 ms), indicating similar onsets of the interruptions in the two conditions, but differences in later bins, probably reflecting the earlier resumption of the tapping in the 4 stimuli condition. This result indicates that the perceptual analysis, here manipulated by the number of presented stimuli, is a contributor to the duration of the action interruption, but not an important one. However, before this conclusion is accepted, alternative accounts should be considered. In particular, it may be contended that the objects presented in the critical trial were all the same. It is certainly possible that the stimuli were perceived as a group and thus analysed as one object (cf. Kahneman, Treisman, $\&$ Gibbs, 1992). If this were the case, there would be little basis to expect 
differences between the two conditions. That is, the results may be different if the number of perceptually differing objects within a display is increased. This was tested in the following three experiments.

\section{EXPERIMENT 2}

In order to test the possibility that the number of stimuli per se may be less important than the number of different stimuli, the number of different stimuli was varied but the total number of stimuli presented was held constant. Thus, in the same stimuli condition, 4 identical stimuli were presented in the surprise trial. In contrast, in the different stimuli condition, 4 different stimuli were presented in that trial.

\section{Method}

Participants. Fifteen women and five men (age: $M=23.4, S D=2.4$ ) participated in this study. Compensation was 2 DM.

Design, materials, stimuli, and procedure. In the same stimuli condition, these were identical to the 4 stimuli condition in Experiment 1. In the different stimuli condition, the stimuli were: (a) a diamond within a rectangular frame, displayed by its outlines (the same stimulus that was used in the same stimuli condition), (b) the same diamond, but displayed as a solid block, (c) a square of the same size as the diamond in the frame, displayed by its outlines, and (d) the same square, but displayed as a solid block.

\section{Results}

Two participants, one from the same stimuli condition and one from the different stimuli condition, were excluded from data analysis because both had above average IRIs $>300 \mathrm{~ms}$ in start and continue trials and no tap in stop trials. Tapping performance of the remaining 18 participants in the nonsurprise trials was very similar to that in Experiment 1 . Tapping speed, as measured by the mean IRI was $114 \mathrm{~ms}(S D=21 \mathrm{~ms})$ in the start trials, $123 \mathrm{~ms}(S D=21 \mathrm{~ms})$ in the continue tapping trials, and $111(S D=24 \mathrm{~ms})$ in the stop trials. Mean RT in the start trials was $364 \mathrm{~ms}(S D=35 \mathrm{~ms})$. The last tap time was $222 \mathrm{~ms}(S D=49 \mathrm{~ms})$. As in Experiment 1, mean eSRT $(M=277 \mathrm{~ms}, S D=54 \mathrm{~ms})$ was significantly shorter than mean RT, $t(17)=8.4, p<.001$.

In the surprise trial, the number of responses recorded until $1200 \mathrm{~ms}$ after signal onset was significantly reduced in the different stimuli condition, $t(8)=$ $5.8, p<.001$, and in the same stimuli condition, $t(8)=5.8, p<.001$. The reduction was stronger with different stimuli $(M=8.0, S D=2.7)$ than with same stimuli $(M=5.2, S D=2.7), t(16)=2.2, p=.02$ (one-tailed). 
The tapping rate was significantly lower than in the corresponding nonsurprise trials within all $200 \mathrm{~ms}$ intervals, $t \mathrm{~s}(17)>2.4, p \mathrm{~s}<.05$, except the first one, $t(17)<1$. To test whether the number of different objects influences the performance in the critical trial, $\Delta_{\text {crit }}$ was computed for each bin as the differences between the critical and the precritical trials. $t$-Tests revealed significant or marginally significant differences in $\Delta_{\text {crit }}$ between the two groups in all bins but the first one and the third one [1st bin, $t(16)<1$; 2nd bin, $t(16)=2.08, p=$ .03 ; 3rd bin, $t(16)<1$; 4th bin, $t(16)=2.26, p=.02$; 5 th bin, $t(16)=2.24, p=$ .02 ; 6th bin, $t(16)=1.74, p=.05$; all tests one-tailed]. In each case, the reduction in tapping performance was higher with different stimuli.

Fifteen of the 18 participants $(83 \%)$ interrupted the tapping. There was no significant difference in the frequency of interruptions between the same and the different-stimuli condition $(78 \%$ vs. $89 \%), \chi^{2}(1 ; N=18)<1$, Fisher's exact test, $p=.50$ (one-tailed).

The last tap time (for those participants who met the criterion for an interruption) was $146 \mathrm{~ms}(S D=123 \mathrm{~ms})$. Last tap time was significantly lower in the surprise trial than in the nonsurprise trials $(M=234, S D=44 \mathrm{~ms}), t(14)=2.7, p$ $=.009$ (two-tailed).

The number of different objects did not significantly affect the last-tap time in the surprise trial, $t(13)<1$. There was also no difference between the two experimental conditions for the surprise ratings, $t(16)=1.1$. The mean surprise rating was $7.7(S D=1.5)$. Finally, there was no difference between the two experimental conditions for the interruption duration, $t(13)=1.1$. The mean duration was $1074 \mathrm{~ms}(S D=265 \mathrm{~ms})$

\section{Discussion}

Experiment 2 replicates the very fast action interruption found in Experiment 1 , again even faster than the intentional interruptions in the precritical trials and a with eSRT of only $201 \mathrm{~ms}$. The number of different objects had a significant impact on the action interruption in two of three analyses: The total number of key presses recorded in the critical trial was lower for the 4 same objects than for the 4 different objects, and there were significant differences between the two groups in $\Delta_{\text {crit }}$. There was also a numerical difference in the computed average duration of the action suspension of $148 \mathrm{~ms}$, which was, however, not significant. The reason for the latter result (i.e., the failure to find a difference in the average duration) is probably due to the fact that this parameter is computed only for those participants who interrupted as determined by the 2 empty bins criterion. Together with the first experiment, the results so far reveal that the difficulty of the perceptual analysis has its impact on the duration of the action interruption, although it is not the most important determinant. 


\section{EXPERIMENT 3}

In Experiments 1 and 2, the surprising stimuli resembled the target display in that all had the frame as a common element, and both comprised horizontal and vertical lines. Thus, some aspects of the obtained results might have been due to the similarity of the target display and the surprising stimuli. For example, with surprising stimuli resembling the action-relevant target display, it might be especially difficult to decide that the surprise stimuli are action-irrelevant (cf. Meyer et al., 1997). The aim of Experiment 3 was to test the validity of this contention. Thus, the surprising stimuli were chosen to be dissimilar to the target display: Schematic facial expressions of emotion. Analogous to Experiment 2, the number of different faces was varied as a between-participants factor.

\section{Method}

Participants. Fourteen women and six men (age: $M=24.4, S D=4.4$ ) participated in this study. Compensation was $2 \mathrm{DM}$.

Design, materials, stimuli, and procedure. These were exactly the same as in Experiment 2; only the stimuli differed. In the same stimuli condition, all four stimuli were neutral faces. In the different stimuli condition, a sad, a surprised, and a friendly face were presented in addition to the neutral face. The faces were computer-generated line drawings taken from an article published by Musterle and Rössler (1986; see also Horstmann, 2001). Figure 4 shows the display in the surprise trial in the different-stimuli condition.

\section{Results}

Tapping performance in the non-surprise trials was very similar to that in the previous experiments. Mean IRI was $110 \mathrm{~ms}(S D=23 \mathrm{~ms})$ in the start trials, 121 $\mathrm{ms}(S D=27 \mathrm{~ms})$ in the continue tapping trials, and $113(S D=30 \mathrm{~ms})$ in the stop trials. Mean RT in start trials was $381 \mathrm{~ms}(S D=40 \mathrm{~ms})$. Mean last tap time was $248 \mathrm{~ms}(S D=46 \mathrm{~ms})$. As in Experiment 1 , mean eSRT $(M=304 \mathrm{~ms}, S D=43$ $\mathrm{ms}$ ) was significantly shorter than mean $\mathrm{RT}, t(19)=8.6, p<.001$.

The number of responses was significantly lower for the surprise trial than for the nonsurprise continue tapping trials in the same stimuli condition (4.6 vs. $11.4), t(9)=8.3, p<.001$, and in the different stimuli condition (3.7 vs. 9.2), $t(9)$ $=6.0, p<.001$, with no difference between the two groups, $t(18)=1.0$. The tapping rate was significantly lower as compared to the corresponding nonsurprise trials within all $200 \mathrm{~ms}$ intervals, $t \mathrm{~s}(19)>2.1, p \mathrm{~s}<.05$, except the first one, $t(19)<1.1$. $t$-Tests revealed no differences in $\Delta_{\text {crit }}$ between the two groups in neither bin, $t \mathrm{~s}<1.48$.

Nineteen of the 20 participants (95\%) interrupted the tapping, although one of these 19 persons might not have interrupted automatically but rather voluntarily, 


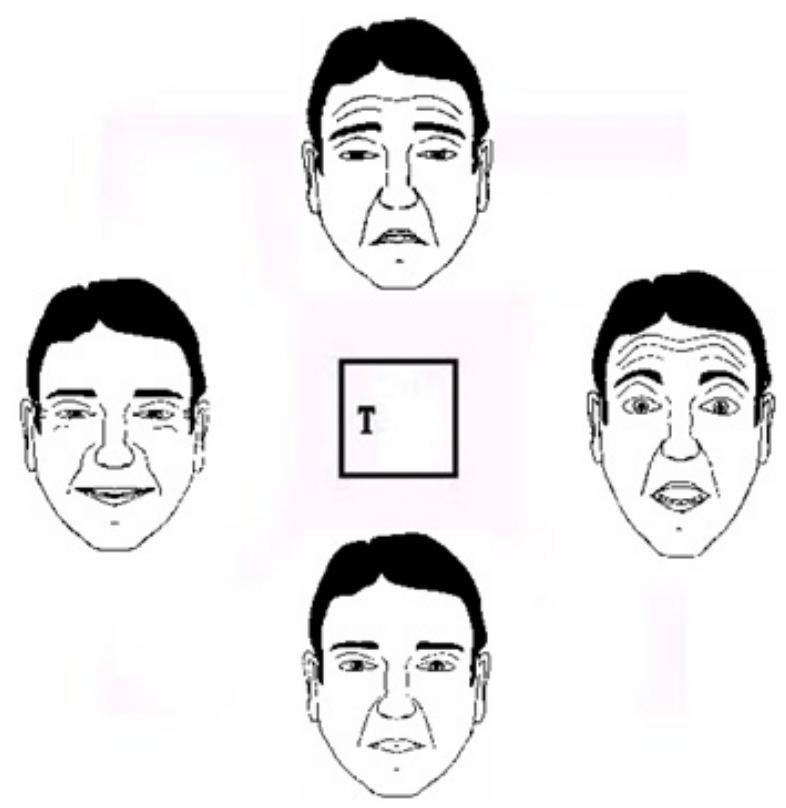

Figure 4. An example of the experimental stimuli used in Experiment 3.

as the last tap time was unusually long $(881 \mathrm{~ms})$. There was no significant difference in the frequency of interruptions between the same and the different stimuli condition $(100 \%$ vs. $90 \%), \chi^{2}(1 ; N=20)<1$, Fisher's exact test $p=.50$ (one-tailed).

The last-tap time (for the 19 participants who met the criterion for an interruption) was $184 \mathrm{~ms}(S D=191 \mathrm{~ms})$. This last-tap time failed to be significantly lower in the surprise trial than in the non-surprise trials $(M=246, S D$ $=46 \mathrm{~ms}$ ), $t(18)=1.4, p=.18$ (two-tailed).

The number of different faces did not significantly affect the last-tap time in the surprise trial, $t(17)<1$. There was also no difference between the two experimental conditions for the surprise ratings, $t(18)=1.1$. The mean surprise rating was $8.0(S D=1.3)$. Finally, there was no difference between the two experimental conditions for the interruption duration, $t(17)<1$. The mean duration was $949 \mathrm{~ms}(S D=332 \mathrm{~ms})$.

\section{Discussion}

Experiment 3 obtained results qualitatively similar to those in Experiments 1 and 2 with respect to the frequencies and the latencies of interruptions, although it differed from Experiments 1 and 2 in that no difference in interruption duration was found (see below). Nearly all participants interrupted the tapping in 
the surprise trial. The interruption latency was very short, although the interruption tended to start somewhat later than in the previous experiments. Experiment 3 generalises the results of Experiments 1 and 2 to a very different stimulus material consisting of irregular, curved lines, rather than geometric figures. Because the parameters (i.e., latency and duration) of the interruption were very similar in all three experiments, it appears rather implausible that the high similarity between the new objects and the target display is an important factor for the interruption.

The mean interruption duration was again about a second. No differences were obtained in the dependent variables between the same and the different stimuli condition. A possible explanation for the absence of a difference-effect may be that the identity of the stimuli in the same stimuli condition in Experiment 2 was very salient due to the simplicity of the stimuli, whereas in the present experiment, the similarity was masked by the complexity of the stimuli.

\section{EXPERIMENT 4}

In Experiments 1-3, multiple objects were presented in both experimental conditions. The aim of Experiment 4 was to test the effect of this feature. Thus, in the multiple stimuli condition, participants received multiple new stimuli as in the previous experiments. In contrast, in the single condition, only one stimulus was presented in the surprise trial.

\section{Method}

Participants. Sixteen women and eight men (age: $M=22.5, S D=3.6$ ) participated in this study. Compensation was 2 DM.

Design, materials, stimuli, and procedure. In the multiple stimuli condition, these were exactly the same as in the different stimuli condition of Experiment 2 . The only difference within the single stimulus condition was that only one new object was presented in the surprise trial. Each of the four different objects presented in the multiple stimuli condition was presented to three participants. The position of this object was always congruent with its position in the multiple condition.

\section{Results}

Tapping performance in the nonsurprise trials was very similar to that in the previous experiments. Mean IRI was $115 \mathrm{~ms}(S D=22 \mathrm{~ms})$ in the start trials, 124 $\mathrm{ms}(S D=26 \mathrm{~ms})$ in the continue tapping trials, and $116(S D=29 \mathrm{~ms})$ in the stop trials. Mean RT in start trials was $392 \mathrm{~ms}(S D=55 \mathrm{~ms})$. Mean last tap time was 
$255 \mathrm{~ms}(S D=67 \mathrm{~ms})$. Mean eSRT $(M=313 \mathrm{~ms}, S D=75 \mathrm{~ms})$ was significantly shorter than mean RT, $t(23)=5.9, p<.001$.

In the surprise trial, the number of responses recorded until $1200 \mathrm{~ms}$ after signal onset was significantly reduced in the single stimulus condition, $t(11)=$ 4.6, $p<.001$, and in the four different stimuli condition, $t(11)=6.5, p<.001$. The reduction was significantly stronger with a single stimulus $(M=6.2, S D=$ 3.3) than with four different stimuli $(M=2.7, S D=2.0), t(24)=3.1, p=.003$ (one-tailed).

In the surprise trial, tapping rate was significantly lower as compared to the corresponding nonsurprise trials within all $200 \mathrm{~ms}$ intervals, $t \mathrm{~s}(23)>4.0, p \mathrm{~s}<$ .001 , except the first, $t<1$, and the last one, $t(23)=1.5, p=.08$ (one-tailed). Except for the first and the second bin, $\Delta_{\text {crit }}$ was significantly higher in the multiple condition, $t \mathrm{~s}(22)>2.10, p<.02$ (one-tailed). In the second bin, $\Delta_{\text {crit }}$ tended to be higher in the multiple stimuli condition, $t(22) 1.62, p=.06$ (onetailed). In the first bin, there was no difference, $t<1$.

Thirteen of the 24 participants $(54 \%)$ interrupted the tapping: four in the single-stimulus condition and nine in the multiple stimuli condition. This difference was significant, $\chi^{2}(1 ; N=24)=4.2, p=.04$.

The last tap time (for those participants who met the criterion for an interruption) was $136 \mathrm{~ms}(S D=80 \mathrm{~ms})$. The last tap time was significantly lower in the surprise trial than in the nonsurprise trials $(M=242, S D=41 \mathrm{~ms}), t(12)=$ $4.4, p=.001$.

Participants in the single stimulus condition tended to stop earlier than in the multiple stimuli condition as indicated by their last tap times (74 ms vs. 164), $t(11)=2.2, p=.05$ (two-tailed). There was no difference between the two experimental conditions for the surprise ratings, $t(21)=1.3$ (one missing value). The mean surprise rating was $6.2(S D=2.2)$. However, the difference between the two experimental conditions for the interruption duration was significant, $t(11)=1.8, p=.05$ (one-tailed). The mean duration (for those participants who met the criterion for an interruption) was longer in the multiple stimuli condition than in the single stimulus condition (1064 ms vs. $796 \mathrm{~ms}$ ).

\section{Discussion}

Experiment 4 confirms and strengthens the assumption that the processing demands imposed by a surprising event are higher if it comprises several different objects rather than one single object, and that this additional demand lengthens the action suspension. The presentation of the single stimulus resulted in less enduring suspensions of the tapping that the presentation of multiple stimuli. The shorter duration of the suspension was probably also the reason why fewer participants met the criterion for an interruption at all in the single stimulus condition. 


\section{GENERAL DISCUSSION}

Four experiments examined the presence, the latency, and the duration, of the action interruption induced by a surprising event (see Table 1). On average, 78\% of the participants interrupted the tapping. That is, the first aim of the present experiments, to directly demonstrate the interrupt function of surprise by an interruption of a continuous action was highly successful.

Several characteristics of surprising events were found to be especially effective or ineffective in inducing a clearly detectable action interruption. In particular, many different stimuli are more effective than one single stimulus, and schematic line drawings of facial expressions are particularly effective. As postulated in the introduction, the likelihood of interruptions as a consequence of surprising events are a joint function of: (a) their potential to elicit surprise at all, that is, the degree of expectation discrepancy, and (b) the duration of the processes of stimulus analysis (exploration and perception), appraisal (attribution and interpretation), and schema updating (learning). The first component of the function (i.e., schema discrepancy) triggers the interruption, whereas the second component (i.e., processes unfolded during the action suspension), if sufficiently enduring, renders the interruption more or less conspicuous: The action suspension must have some minimal duration to be distinguishable from the naturally occurring IRIs between the key depressions during the tapping task. Both factors will be discussed later after evaluating the results concerning the interruption latency.

That the action interruption was involuntary is implied by the fact that the interruption occurred despite the presence of a continue tapping signal. More precisely, the interruption was contrary to intentions (assuming that the intentions of the participants conformed to the instructions, which emphasised that

TABLE 1

Summary of the results in Experiments 1-4

\begin{tabular}{lcccc}
\hline Experiment & $\begin{array}{c}\text { Frequency of } \\
\text { interruptions } \\
(\%)\end{array}$ & $\begin{array}{c}\text { Latency of } \\
\text { interruption } \\
\text { eSRT (ms) }\end{array}$ & $\begin{array}{c}\text { Duration of } \\
\text { interruption } \\
(\mathrm{ms})\end{array}$ & $\begin{array}{c}\text { Surprise } \\
\text { rating }\end{array}$ \\
\hline 1 & $79 \%$ & 222 & 974 & 7.0 \\
2 & $83 \%$ & 202 & 1074 & 7.7 \\
3 & $95 \%$ & 240 & 949 & 8.0 \\
4 & $54 \%$ & 193 & 981 & 6.2 \\
Mean & $78 \%$ & 214 & 995 & 7.2 \\
\hline
\end{tabular}

Note: eSRT, \& timation of stop reaction time.

Exp. $1=4$ vs. 8 geometric objects; Exp. 2 = same vs. different multiple geometric objects; Exp. 3 = same vs. different multiple nongeometric objects (faces); Exp. $4=1$ object vs. 4 objects. 
tapping should not be interrupted or suspended until the presentation of a stop signal). This result supports the hypothesis that the action interruption in surprise is automatic and not intentional, as implied by the evolved surprise-module hypothesis.

\section{Interruption latency}

The interruption latency in the present experiments was very short, with an average of $214 \mathrm{~ms}$ for the estimated stop reaction time in the critical trial. Moreover, the interruption latency in the critical trial was also shorter than the latency for intentional interruptions in the precritical trials. This short latency is consistent with the assumption that the components of surprise are controlled by an evolutionary ancient surprise-module that is activated reflexively by the discrepancy-detection process.

The short latency of the action interruption can be compared with the latencies of other processes that are similar with respect to their probable evolutionary origin and their hard-wired, reflexive nature. First, with an average of about $200 \mathrm{~ms}$, the action interruption is remarkably slower than an eye-blink instigated by a loud noise in startle (which is below $50 \mathrm{~ms}$ for auditory probes, e.g., Larsen, Ruffallo, Nietert, \& Davidson, 2000, and about 50-80 ms for visual probes, e.g., Blumenthal et al., 2005). This is consistent with the assumption that the mechanisms underlying startle and the action interruption in surprise are different (e.g., Charlesworth, 1969; Meyer \& Niepel, 1994), and is inconsistent with the assumption that startle is a stronger variant of surprise (Tomkins, 1962). Of course, the surprise stimuli in the present experiments did not instantiate startle probes, because their intensities were far too weak. Also, startle responses can be elicited repeatedly with the same stimulus, whereas frequently repeated events lose their surprising character (Meyer \& Niepel, 1994; Schützwohl, 1993).

The latency of the action interruption can also be compared with the latency of the orienting response (OR). The OR is often supposed to occur in conditions similar to those assumed here for surprise (e.g., Öhman, 1979), although probably not all stimuli that elicit an OR also elicit surprise (cf. Meyer \& Niepel, 1994). In particular, the OR is often examined by presenting a stimulus that perceptually deviates from preceding stimuli, because it is assumed that the OR is triggered by the discrepancy between the OR stimulus and the preceding stimuli, which is similar to the hypothesised conditions of surprise. On the other hand, the OR is often tested with repeated presentations of the same orienting stimulus, implying that the orienting stimulus is not unexpected, but rather awaited or anticipated (notwithstanding that the temporal position of the OR stimulus within the stimulus sequence may still be unpredictable). In contrast, theoretical consideration and empirical evidence suggest that surprise cannot be 
elicited repeatedly with the same stimulus (Horstmann \& Ansorge, in press; Meyer \& Niepel, 1994; Schützwohl, 1993).

Regarding the latencies of indices of surprise and the OR, it appears that the physiological changes that index the OR are usually an order of magnitude slower than the action interruption. For example, the bradycardia (heart rate deceleration) evoked by a stimulus change starts not earlier than $1500 \mathrm{~ms}$ after the stimulus with an announced change, and around $500 \mathrm{~ms}$ with an unannounced change (Niepel, 2001, fig. 3). The same is true of the galvanic skin response, where changes are scored within a time window of several (e.g., 1-5) seconds after stimulus onset (Barry, 1990; Niepel, 2001), although the increase in skin conductance appears to begin about 1000-1500 ms after stimulus onset (Barry, 1990, fig. 2). That is, as compared to these components of the OR, the interruption latency of $220 \mathrm{~ms}$ is relatively short. Of course, these generalisations should be regarded with caution because they are based on comparisons between different experimental paradigms and stimuli; future research may compare the latencies of the components of surprise and related psychophysiological states directly within the same paradigms. This is particularly relevant because the inhibition of ongoing activity has been postulated for the OR, though little or no direct experimental evidence has been obtained to date (cf. Rohrbaugh, 1984).

The interrupt latency of about $200 \mathrm{~ms}$ in the present experiments is consistent with previous studies using the RT delay as the index of action interruption (e.g., Meyer et al., 1991; Niepel et al., 1994, Schützwohl, 1998). In these studies, a surprising stimulus had only a very weak delaying effect on RT when presented simultaneously with the target of the RT task, but a strong delaying effect when presented $500 \mathrm{~ms}$ in advance. Niepel et al. (1994) found a corresponding effect with an auditory stimulus and a SOA of $200 \mathrm{~ms}$.

Horstmann (2002; in press-a) assessed the latency of another component of surprise - the refocusing of attention - and derived an estimate of 300-400 ms. The different estimates could be due to different types of surprising events. Horstmann's (2002) participants basically searched for a red target letter among red distractor letters in the precritical trials, and the surprise stimulus was a green target letter among red distractor letters in the critical trial. The surprising event was thus solely defined by colour difference (i.e., it was discrepant to expectancy only with respect to colour), whereas the presence of a stimulus at that spatial position was expectancy-congruent. This is different from the present experiments, where the mere presence of the stimuli was presumably expectancy-discrepant. The obtained differences in latencies are consistent with the hypothesis that the choice of the surprise stimuli has some influence on the interruption latency, and that the latency of the action interruption is at its minimum if the very arrival of new objects is expectancy-discrepant.

The detection of the onset of a new stimulus is presumably an elementary and fast process (Breitmeyer \& Ganz, 1976), and new objects have even been 
assumed to capture attention in their own right ("onset capture"; e.g. Enns, Austen, Di Lollo, Rauschenberger, \& Yantis, 2001; Yantis, 1993; Yantis \& Hillstrom, 1994; but see Folk, Remington, \& Johnston, 1992, 1993). Thus, information about the appearance of a new object may be faster available to the discrepancy detector than other information about the object (such as colour). Alternatively, the new objects may have quickly attracted attention due to "onset capture" (i.e., prior, or parallel to "surprise capture", that is, the attraction of attention by surprising stimuli). Whether onset capture is possible under the present experimental conditions, however, is debatable. Onset capture requires attention to be distributed over the visual field, and fails to show up if attention is already focussed on a particular spatial position (Theeuwes, 1991; Yantis \& Jonides, 1990), unless the new object shares perceptual features of the to-be-attended-to stimulus (Folk, Leber, \& Egeth, 2002). In the present experiments, attention was not spatially distributed over the screen area where the new objects appeared, but focussed on the area where the letters appeared. The letter signals were rather small and the identification of letters is usually thought to require focused attention (e.g., Treisman \& Gelade, 1980). Moreover, the letters appeared in a restricted area in the centre of the display with no spatial uncertainty about the spatial position of the next letter. Similarity between the new objects and the task-relevant letters (or the frame that surrounded them) was also not a pertinent factor for the interruption, as the new objects interrupted the tapping even when they were maximally dissimilar to the to-be-attended-to signals $\mathrm{T}$ and $\mathrm{H}$, or to the frame in which the signals appeared (Experiment 3 ). Thus, there are reasons to doubt that onset capture alone can explain the short interruption latency in the present experiments.

\section{Interruption duration}

The mean interruption duration was about 1 second, but was influenced by the number and the heterogeneity of the surprise stimuli. This was predicted on the assumption that the interruption duration is influenced by the duration of effortful processes of the analysis, evaluation, and schema integration of the surprising events. This assumption was confirmed in several experiments (e.g., Horstmann \& Schützwohl, 1998; Meyer et al., 1997; Schützwohl, 1998). Whereas prior experiments predominantly tested the cognitive processes of stimulus evaluation and schema change, the present experiments were aimed at testing the perceptual processes of stimulus analysis, which are assumed to be the precondition for the more complicated higher level processes (cf. Meyer et al., 1997). It was reasoned that manipulations of the number and heterogeneity of stimuli primarily changed the demand for their perceptual analysis. Both the number of stimuli and their homogeneity had some nontrivial impact on the interruption duration, amounting up to about $250 \mathrm{~ms}$ or $25 \%$ of the total interruption duration in Experiment 4. This implies, in turn, that at least $75 \%$ of the 
total interruption duration is due to other processes, most probably to appraisals and schema-change processes.

The assumption that the variations in the stimuli affect the stimulus analysis exclusively is probably an oversimplification, but at present there is little basis to predict other effects. One might think that some of the variations affected the duration of the schema-updating processes. However, schema strength, which is a schema's resistance to change (Horstmann \& Schützwohl, 1998; Schützwohl, 1998), was constant for all participants: All saw the same number of precritical trials and the same degree of stimulus variability in the precritical trials (cf. Schützwohl, 1998). Moreover, according to schema theories (e.g., Rumelhart, 1984; Schützwohl, 1998), the effort to incorporate 4 or 8 identical stimuli (Experiment 1) into the schema should be the same, because - other things being equal - the number of the stimuli would be stored as a value in a variable. Also, the heterogeneous stimuli (Experiments 2 and 3) would be represented by a variable while the homogenous stimuli would be represented by a constant (cf. Schützwohl, 1998).

\section{Is the action interruption caused by the reorienting of attention?}

The orienting of attention and the interrupting of cognitive and motor processes are assumed to be partly linked in function: The orienting of attention provides access to higher level processes, and the interruption frees the processing mechanism from other potentially interfering cognitive processes. Note that this functional linkage is not necessarily complete, because the action interruption may serve other functions as well: Most importantly, because a surprising event may require immediate action, it would be advantageous if the cognitive-motor action-execution processes were not occupied with other motor tasks (Pashler, 1994). Moreover, suspending action may be a protective response, preventing the organism from further approaching the yet nonappraised unexpected object, or preventing the organism from attracting the attention by a possible animate originator of the surprising event sensitive to movements.

It is possible that the mechanisms of orienting and interrupting are not only functionally linked, but also causally. In particular, the action interruption may be nothing else than the reflection of the withdrawal of processing resources caused by the reorienting of attention. When considering this possibility, it is important to recall that attention is used to denote different mechanisms in different contexts, and is not a unitary concept. One concept of attention is that of a mental spotlight that can be used to highlight stimuli successively in order to allow a faster and more accurate perceptual analysis (e.g., Posner, 1980). For attention conceived in this way, shifts of attention should automatically interrupt motor processes only if the motor processes directly depend on continuous visual input. For example, if the task is to follow an unpredictably moving 
stimulus on a computer screen with the mouse cursor, orienting attention away from the moving stimulus will reduce the accuracy of the pursuit performance. In contrast, continuous tapping, as many other activities like walking or bicycling, do not directly depend on visual input, and therefore, attention may be focused anywhere in space during the execution of these acts. For this reason, the mere shift of visuospatial attention to the new objects in the critical trial of the present experiments cannot adequately explain the action interruption.

Another concept of attention is that of a processing resource that is necessary for action control. For example, according to bottleneck models of attention (e.g., Pashler, 1994; Welford, 1952), attention is needed for the selection of responses among alternatives, or for the initiation of the selected response (response selection/initiation, in turn, is assumed to be strictly limited, constituting a bottleneck for processing). This concept of attention is relevant for the analysis of the interruption in surprise because, from an evolutionary perspective, it would be highly adaptive to free the processing resources necessary to evaluate different possible courses of action, and to initiate one of them quickly. In other words, demanding the resources for response selection and initiation would be a prime candidate for a biological function of the action interruption. However, in the present case it is rather unlikely that the interruption was caused by the withdrawal of the response selection and initiation resources, because in the tapping task, these resources are needed only when the course of the action is changed, that is, when the tapping is started or stopped (Horstmann, 2003). Indeed, tapping is a classic example of a simple action that is barely demanding (Pashler, 1994), which can be easily demonstrated by trying to tap while thinking or doing mental arithmetic. To emphasise, in simple, repetitive activities like tapping, walking, or cycling, we do not have to pay attention to the action, but can have the action run on autopilot (Logan, 1994).

The present discussion reveals that prominent views on attention do not support the possibility that the action interruption is the mere consequence of attending elsewhere. A possible problem pertaining both to the experimental data and to the theories is that only expected events have been considered. It is possible that attending to expected events is so little demanding that relatively automatic processes are not disrupted, whereas the demand of attentional resources by unexpected events is so high that even processes that run on the metaphorical autopilot are disrupted.

\section{Surprise ratings}

The rated surprise in the present experiments was remarkably high, with a mean rating of 7.2 on a scale ranging from 0 to 10 , indicating a high degree of surprise. The high surprise ratings render the concern unconvincing that the participants were not actually surprised but reported surprise only because of demand characteristics of the experimental setting. Previous research, using similar 
experimental tasks (i.e., computer controlled RT tasks) and similar rating scales to assess subjective surprise already revealed that the mean surprise ratings were close to zero when no unexpected event was presented in the experiment (e.g., Meyer et al., 1991; Schützwohl, 1998). This indicates that the demand characteristics to indicate surprise untruly are not very high in this type of setting. A more sophisticated concern might be that the presentation of an unexpected event itself induces demand characteristics to report surprise, because the connection between unexpectedness and surprise is part of the semantics of the concept of surprise. However, in this case, it should have been sufficient to indicate a low degree of surprise to conform to the demand characteristics. Finally, the experimenter was not interacting with the participants, thus minimising social influence. To conclude, the overall setting did not encourage participants to make the surprise ratings according to assumed expectations of the experimenter. Rather, it is reasonable to assume that the presentation of the new objects, though instantiating a very simple type of unexpected event, truly elicited surprise.

\section{Is surprise an emotion?}

As already noted by Desai (1939), there is no agreement among theorists on the question whether surprise is an emotion. Evolutionary oriented researchers usually answer the question in the affirmative: surprise is an emotion, or more precisely, a basic emotion, because surprise solves a specific adaptive problem (e.g. Darwin, 1872; Meyer et al., 1997; Plutchik, 1980). Additional evidence from an evolutionary perspective is that surprise is one of the six or seven emotions that are signalled by inborn, universal facial signs ("facial expressions of emotion"; e.g., Ekman, 1992). However, some theorists do not regard surprise as an emotion, because according to their definition, emotions are always valenced, and surprise can be neutral as well as positive or negative (e.g., Lazarus, 1991; Ortony, Clore, \& Collins, 1988). For example, Lazarus (1991) argues that emotions arise after events are appraised as relevant for the organism's well-being, which is not true for surprise (i.e., surprise is elicited by expectancy discrepancy before an evaluation of implications for well-being). According to Lazarus, surprise is a preemotion that prepares the organism for emotion-relevant appraisals.

As pointed out by Meyer, Reisenzein, and Niepel (2000), classification of surprise as an emotion or nonemotion often relies exclusively on one single criterion (e.g., the presence of a characteristic facial expression, hedonic valence, or relevance for well-being of the perceiver). Meyer et al. (2000) suggest that using several converging criteria for prototype emotions is more adequate (see also, Russell, 1991). Surprise shares many attributes of prototype emotions: (a) an unique qualia, that is, subjective experience, which can vary in intensity, (b) object-directedness, that is, one is usually surprised about some- 
thing, (c) elicitation through a certain stimulus evaluation or appraisal, (d) expression through a characteristic facial display, (e) a plausible function that solves a recurrent adaptive problem, (f) an old phylogenetic origin. Because surprise shares so many attributes with emotions like happiness, anger, fear, or sadness, Reisenzein, Meyer, and Schützwohl (1996) have suggested that research on surprise may even become a paradigm for emotion research in much the same way as conditioned fear already is (e.g., LeDoux, 1998). The advantages for examining surprise are: (a) it can be elicited relatively easily in the laboratory, with the advantages of precise stimulus control, in particular with respect to timing; (b) because it can be elicited in the laboratory, it is possible to assess surprise with a number of different methods, including self-reports, physiological data, nonverbal expressions, and behavioural data, such as the focusing of attention and the interruption of ongoing behaviour; (c) because surprise is not harmful or strenuous, ethical problems regarding emotion induction with human participants can be largely avoided.

The present experiments were intended as a further step in the direction of an in-depth analysis of surprise. They introduce a new paradigm with one observable indicator of surprise that can be easily and reliably measured, and they set a first stage for a process analysis of changes induced by surprising events in terms of their temporal patterning.

Manuscript received 2 December 2004 Revised manuscript received 20 July 2005

\section{REFERENCES}

Barry, R. J. (1990). Scoring criteria for response latency and habituation in electrodermal research: A study in the context of the orienting response. Psychophysiology, 27, 94-100.

Blumenthal, T. D., Cuthbert, B. N., Filion, D. L., Hackley S., Lipp, O. V., \& Van Boxtel, A. (2005). Committee report: Guidelines for human startle eyeblink electromyographic studies. Psychophysiology, 42, 1-15.

Breitmeyer, B. G., \& Ganz, L. (1976). Implications of sustained and transient channels for theories of visual pattern masking, saccadic suppression, and information processing. Psychological Review, $83,1-36$.

Charlesworth. W. R. (1969). The role of surprise in cognitive development. In D. Elkind \& J. H. Flavell (Eds.), Studies in cognitive development (pp. 257-314). Oxford, UK: University Press.

Darwin, C. (1872). The expression of the emotions in man and animals. London: Murray.

Desai, M. M. (1939). Surprise: A historical and experimental study. British Journal of Psychology: Monograph Supplements, 7(22).

Eibl-Eibesfeld, I. (1997). Die Biologie des menschlichen Verhaltens [The biology of human behaviour]. Grundriss der Humanethologie. München: Piper.

Ekman, P. (1972). Universals and cultural differences in facial expressions of emotion. In J. Cole (Ed.), Nebraska symposium on motivation (Vol. 19, pp. 207-283). Lincoln: University of Nebraska Press.

Ekman, P. (1992). Are there basic emotions? Psychological Review, 99, 550-553. 
Enns, J. T, Austen, E. L, Di Lollo, V., Rauschenberger, R., \& Yantis, S. (2001). New objects dominate luminance transients in setting attentional priority. Journal of Experimental Psychology: Human Perception and Performance, 27, 1287-1302.

Folk, C. L., Leber, A. B., \& Egeth, H. E. (2002). Made you blink! Contingent attentional capture produces a spatial blink. Perception and Psychophysics, 64, 741-753.

Folk, C. L., Remington, R. W., \& Johnston, J. C. (1992). Involuntary covert orienting is contingent on attentional control settings. Journal of Experimental Psychology: Human Perception and Performance, 18, 1030-1044.

Folk, C. L., Remington, R. W., \& Johnston, J. C. (1993). Contingent attentional capture: A reply to Yantis (1993). Journal of Experimental Psychology: Human Perception and Performance, 19, 682-685.

Frijda, N. H. (1986). The emotions. New York: Cambridge University Press.

Frijda, N. H., Kuipers, P., \& ter Schure, E. (1989). Relations among emotion, appraisals, and emotional action readiness. Journal of Personality and Social Psychology, 57, 212-228.

Horstmann, G. (2001). Die Unterbrechungsfunktion der Überraschung: Ein neues experimentelles Paradigma und ein Test der Automatizitätshypothese. [The interrupt-function of surprise: A new experimental paradigm and a test of the automaticity hypothesis]. Unpublished doctoral dissertion, Bielefeld University), Germany.

Horstmann, G. (2002). Evidence for attentional capture by a surprising color singleton in visual search. Psychological Science, 13, 499-505.

Horstmann, G. (2003). The psychological refractory period of stopping. Journal of Experimental Psychology: Human Perception and Performance, 29, 965-981.

Horstmann, G. (in press-a). The time course of intended and unintended orienting of attention. Psychological Research/Psychologische Forschung.

Horstmann, G. (in press-b). Attentional capture by an unannounced color singleton depends on expectation discrepancy. Journal of Experimental Psychology: Human Perception and Performance.

Horstmann, G., \& Ansorge, U. (in press). Attentional capture by rare singletons. Visual Cognition.

Horstmann, G., \& Schützwohl, A. (1998). Zum Einfluss der Verknüpfungsstärke von Schemaelementen auf die Stärke der Überraschungsreaktion [Effect of associative strength of schema elements on intensity of startle reaction]. Zeitschrift für Experimentelle Psychologie, 45, 203-217.

Izard, C. E. (1977). Human emotions. New York: Plenum.

Kahneman, D., Treisman, A., \& Gibbs, B. J. (1992). The reviewing of object files: Object-specific integration of information. Cognitive Psychology, 24, 175-219.

Larson, C. L., Ruffalo, D., Nietert, J. Y., \& Davidson R. J. (2000). Temporal stability of the emotionmodulated startle response. Psychophysiology, 37, 92-101.

Lazarus, R. S. (1991). Emotion and adaptation. New York, NY: Oxford University Press.

LeDoux, J. (1998). The emotional brain. London: Phoenix.

Leventhal, H., \& Scherer, K. R. (1987). The relationship of emotion and cognition: A functional approach to a semantic controversy. Cognition and Emotion, 1, 3-28.

Logan, G. D. (1994). On the ability to inhibit thought and action. A users' guide to the stop signal paradigm. In D. Dagenbach \& T. H. Carr (Eds.), Inhibitory processes in attention, memory, and language (pp. 189-239). San Diego, CA: Academic Press.

McDougall, W. (1908). An introduction to social psychology. London: Methuen.

Meyer, W.-U., \& Niepel, M. (1994). Surprise. In V. S. Ramachandran (Ed.), Encyclopedia of human behavior (Vol. 4, pp. 353-358). Orlando: FL: Academic Press.

Meyer, W.-U., Niepel, M., Rudolph, U., \& Schützwohl, A. (1991). An experimental analysis of surprise. Cognition and Emotion, 5, 295-311.

Meyer, W.-U., Reisenzein, R., \& Niepel, M. (2000). Überraschung [Surprise]. In J. H. Otto, H. A. Euler, \& H. Mandl (Eds.), Emotionspsychologie. Ein Handbuch (pp. 253-263). Weinheim: Beltz. 
Meyer, W.-U., Reisenzein, R., \& Schützwohl, A. (1997). Toward a process analysis of emotions: The case of surprise. Motivation and Emotion, 21, 251-274.

Musterle, W., \& Rössler, O. E. (1986). Computer faces: The human Lorenz matrix. BioSystems, 19, 61-80.

Neisser, U. (1976). Cognition and reality: Principles and implications of cognitive psychology. San Francisco: Freeman.

Niepel, M. (2001). Independent manipulations of stimulus change and unexpectedness dissociates indices of the orienting response. Psychophysiology, 38, 1-8.

Niepel, M., Rudolph, U., Schützwohl, A., \& Meyer, W.-U. (1994). Temporal characteristics of the surprise reaction induced by schema-discrepant visual and auditory events. Cognition and Emotion, 8, 433-452.

Öhman, A. (1979). The orienting response, attention and learning: An information-processing perspective. In H. D. Kimmel, E. H. van Olst, \& J. F. Orlebeke (Ed.), The orienting reflex in humans (pp. 443-471) Hillsdale, NJ: Erlbaum.

Öhman, A., \& Mineka, S. (2001). Fears, phobias, and preparedness: Toward an evolved module of fear and fear learning. Psychological Review, 108, 483-522.

Ortony, A., Clore, G. L., \& Collins, A. (1988). The cognitive structure of emotions. New York: Cambridge University Press.

Panksepp, J. (1992). A critical role for "affective neuroscience" in resolving what is basic about basic emotions. Psychological Review, 99, 554-560.

Pashler, H. (1994). Dual-task interference in simple tasks: Data and theory. Psychological Bulletin, 116, 220-244.

Plutchik, R. (1980). Emotion: A psychoevolutionary synthesis. New York: Harper \& Row.

Plutchik, R. (1984). Emotions: A general psychoevolutionary theory. In K. R. Scherer \& P. Ekman (Eds.), Approaches to emotion (pp. 197-219). Hillsdale, NJ: Erlbaum.

Plutchik, R. (2003). Emotions and life. Washington, DC: APA.

Posner, M. I. (1978). Chronometric explorations of mind. Hillsdale, NJ: Erlbaum.

Posner, M. I. (1980). Orienting of attention. Quarterly Journal of Experimental Psychology, 32, $3-25$.

Reisenzein, R. (2000). Exploring the strength of association between the components of emotion syndromes: The case of surprise. Cognition and Emotion, 14, 1-38.

Reisenzein, R. (2001). Appraisal processes conceptualized from a schema-theoretic perspective: Contributions to a process analysis of emotions. In K. R. Scherer, A. Schorr, \& T. Johnstone (Eds.), Appraisal processes in emotion: Theory, methods, research (pp. 187-201). Oxford, UK: Oxford University Press.

Reisenzein, R., \& Horstmann, G. (in press). Emotion. In H. Spada (Ed.), Lehrbuch Allgemeine Psychologie (3rd ed.). Bern: Huber.

Reisenzein, R., Meyer, W.-U., \& Schützwohl, A. (1996). Reactions to surprising events: A paradigm for emotion research. In N. Frijda (Ed.), Proceedings of the 9th conference of the International Society for Research on Emotions (pp. 292-296). Toronto: ISRE.

Rohrbaugh, J. W. (1984). The orienting reflex in humans. In R. Parasuraman \& D. R. Davies (Ed.), Varieties of attention (pp. 323-373) Orlando, FL: Academic Press.

Roseman, I. J. (1991). Appraisal determinants of discrete emotions. Cognition and Emotion, 5, 161-200.

Roseman, I. J., Antoniou, A. A., \& Jose, P. E. (1996). Appraisal determinants of emotions: Constructing a more accurate and comprehensive theory. Cognition and Emotion, 10, 241-277.

Rumelhart, D. E. (1984). Schemata and the cognitive system. In R. S. Wyer \& T. K. Srull (Eds.), Handbook of social cognition (Vol. 1, pp. 161-188). Hillsdale, NJ: Erlbaum.

Rumelhart, D. E., \& Norman, D. A. (1978). Accretion, tuning, and restructuring: Three modes of learning. In J. W. Cotton \& R. Klatzky (Eds.), Semantic factors in cognition (pp. 37-53). Hillsdale, NJ: Erlbaum. 
Russell, J. A. (1991). In defense of a prototype approach to emotion concepts. Journal of Personality and Social Psychology, 60, 37-47.

Scherer, K. R. (1984a). Emotion as a multicomponent process: A model and some cross-cultural data. In P. Shaver (Ed.), Review of personality and social psychology (pp.37-63). Beverly Hills, CA: Sage.

Scherer, K. R. (1984b). On the nature and function of emotion: A component process approach. In K. R. Scherer \& P. Ekman (Eds.), Approaches to emotion (pp. 293-317). Hillsdale, NJ: Erlbaum.

Schützwohl, A. (1993). Schemata und Überraschung: Untersuchungen zum Zusammenwirken von Kognition und Emotion [Schemata and surprise: Studies on the interaction of cognition and emotion]. Dissertation, Bielefeld University, Germany.

Schützwohl, A. (1998). Surprise and schema strength. Journal of Experimental Psychology: Learning, Memory, and Cognition, 24, 1182-1199.

Schützwohl, A., \& Krefting, E. (2001). Die Struktur der Intensität von Überraschung [The structure of the intensity of surprise]. Zeitschrift für experimentelle Psychologie, 48, 41-56.

Shand, A. F. (1914). The foundations of character. London: MacMillan.

Stiensmeier-Pelster, J., Martini, A., \& Reisenzein, R. (1995). The role of surprise in the attribution process. Cognition and Emotion, 9, 5-31.

Teigen, K. H., \& Keren, G. (2003). Surprises: low probabilities or high contrasts? Cognition, 87, $55-71$.

Theeuwes, J. (1991). Exogenous and endogenous control of attention: The effect of visual onsets and offsets. Perception and Psychophysics, 49, 83-90.

Tomkins, S. S. (1962). Affect, imagery, consciousness: Vol. 1. The positive affects. New York: Springer.

Tomkins, S. S. (1984). Affect theory. In K. R. Scherer \& P. Ekman (Eds.), Approaches to emotion (pp. 163-195). Hillsdale, NJ: Erlbaum.

Tooby, J., \& Cosmides, L. (2000). Evolutionary psychology and the emotions. In M. Lewis \& J. M. Haviland-Jones (Eds.), Handbook of emotions (2nd ed., pp. 91-115). New York: Guilford Press.

Treisman, A. M., \& Gelade, G. (1980). A feature-integration theory of attention. Cognitive Psychology, 12, 97-136.

Weiner, B. (1986). An attributional theory of motivation and emotion. New York: Springer.

Welford, A. T. (1952). The "psychological refractory period"' and the timing of high-speed performance-A review and a theory. British Journal of Psychology, 43, 2-19.

Wilcocks, R.-W. (1928). The effect of an unexpected heterogeneity on attention. Journal of General Psychology, 1, 286-319.

Wolfe J. (1998). Visual search. In Pashler H. (Ed.), Attention (pp. 13-73). London UK: University College London Press.

Yantis, S. (1993). Stimulus-driven attentional capture and attentional control settings. Journal of Experimental Psychology: Human Perception and Performance, 19, 676-681.

Yantis, S., \& Hillstrom, A. P. (1994). Stimulus-driven attentional capture: Evidence from equiluminant visual objects. Journal of Experimental Psychology: Human Perception and Performance, 20, 95-107.

Yantis, S., \& Jonides, J. (1990). Abrupt visual onsets and selective attention: Voluntary versus automatic allocation. Journal of Experimental Psychology: Human Perception and Performance, $16,121-134$. 